\title{
The influence of $\boldsymbol{N}$-acetylneuraminic acid on the properties of human orosomucoid
}

\author{
Mark L. FRIEDMAN, Joseph R. WERMELING and H. Brian HALSALL* \\ Department of Chemistry, University of Cincinnati, Cincinnati, OH 45221-0172, U.S.A.
}

\begin{abstract}
Little is known of the relationships that may exist among the three principal functionalities of glycoproteins. Orosomucoids of closely defined $N$-acetylneuraminic acid content were examined for evidence of influence of $N$-acetylneuraminic acid content on the physical properties of the glycoprotein. Fluorescence spectroscopy gave no indication of conformational change in the protein core upon desialylation. Small changes in the chromatographic partition coefficient, $\sigma$, and thermal stability, $T_{\mathrm{d}}$, are interpreted to reflect loss of water of hydration and increased glycan stem-protein interaction without a major repositioning of the chains. Ligand-binding measurements indicate no alteration in the hydrophobic binding domain and a possible interaction between chlorpromazine and $N$-acetylneuraminic acid. All changes seen are progressive and occur through a region where changes in biological activity are not found. It is suggested that the dependence of biological activity on $\mathrm{N}$-acetylneuraminic acid content in orosomucoid reflects, not coupled changes in protein conformation, but a charge-density-related interaction such that, below a contribution of four or five $N$-acetylneuraminic acid residues, activity is modified.
\end{abstract}

\section{INTRODUCTION}

Glycoproteins are unique in that within a single molecule there are present three functionalities: the polypeptide core, the antennary glycan chains and the sialic acid termini of those chains. Until very recently, the importance of carbohydrates in glycoprotein functions has been largely ignored, partly because of their complex nature, and also because of a general and erroneous (Lawson et al., 1983) belief that the presence of the carbohydrate was merely to confer solubility to the protein. However, glycan chains of proteins have been shown to influence protein-protein interactions (Varghese et al., 1983; Olden et al., 1982), and to be involved in both the recognition of the protein by a variety of physiological systems (Marshall \& Williams, 1978) and in the maintenance of conformational stability of the protein (Montreuil, 1982; Sutton \& Phillips, 1983). Little is known of the inter-relationships that may exist between these functionalities. In general, we may consider three possible interactions: (1) the localized attachment of the sialylated glycan chains preserves a functional conformation of the polypeptide, (2) the physiological function of the molecule involves directly both the sialylated glycan and polypeptide, with or without the presence of (1), or (3) there is no functional linkage between the sialylated or asialo glycan chain and the polypeptide. Of these, (2) has been suggested as being least likely (Olden $e t$ al., 1982).

Human OMD contains a polypeptide of $M_{\mathrm{r}} 21000$ and various glycan chains. Within a population of OMD molecules, $10-15 \%$ possess only biantennary glycan chains, with tri-/tetra-antennary chains providing the remaining 85-90\% (Bayard \& Kerckaert, 1980; Perkins et al., 1985). The glycans are attached $N$-glycosidically to asparagine residues located primarily on putative $\beta$-turns of the polypeptide backbone (Montreuil, 1982). Each branch is terminated by an NeuAc residue.

In the search for the physiological function of this molecule, various biological activities have been reported (Franzblau et al., 1976; Costello et al., 1979a; Andersen et al., 1980; Friedman, 1983), but none as yet has been shown to be of convincing physiological significance. In such investigations, an assessment is often made of the relative activities of OMD molecules containing different amounts of NeuAc. This is done because NeuAc may be involved in charge interactions between a variety of biological macromolecules (Reutter et al., 1982), and also because of the possible physiological import in those disease states in which the concentrations of NeuAc-poor OMD increase and are maintained in vivo for prolonged periods of time (Rudman et al., 1972; Marshall \& Williams, 1978). The results suggest that an interaction of one of the types described above may exist between the sialylated glycan chains and the polypeptide core. For example, it was found that the removal of NeuAc increased the immunogenicity of OMD and its ability to modulate T-lymphocyte reactivity to the mitogens phytohaemagglutinin and concanavalin A (Costello et al., 1979a,b) but decreased its ability both to inhibit the heparin-accelerated antithrombin III-mediated inactivation of thrombin and Factor Xa (Andersen et al., 1980), and to promote collagen fibril formation (Franzblau et al., 1976). In the work now described here we have prepared OMDs of closely defined NeuAc content, and looked for direct evidence of conformational change in the polypeptide as a result of desialylation. In particular, we sought abrupt change in the property being measured that might be correlated with changes in the biological activities mentioned above.

Abbreviations used: OMD, orosomucoid ( $\alpha_{1}$-acid glycoprotein); NeuAc, $N$-acetylneuraminic acid (sialic acid).

* To whom correspondence should be addressed. 


\section{MATERIALS AND METHODS}

\section{Chemicals and buffers}

Chlorpromazine hydrochloride, dipyridamole hydrochloride and Clostridium perfringens neuraminidase were purchased from Sigma Chemical Co. Spin-labelled propranolol was purchased from Molecular Probes. Electrophoresis-grade acrylamide was obtained from Bio-Rad Laboratories, optical-grade $\mathrm{CsCl}$ from Calbiochem, certified A.C.S. KI from Fisher Scientific Co., and succinimide from Eastman Kodak Co. All buffer salts were reagent grade or better. Phosphate-buffered saline consisted of $0.14 \mathrm{M}-\mathrm{NaCl}, 10 \mathrm{mM}$-sodium phosphate and $1 \mathrm{~mm}-\mathrm{Na}_{2}$ EDTA, pH 7.4.

\section{Protein preparation}

OMD was prepared from the urine of individuals with nephrotic syndrome and characterized as described previously (Halsall et al., 1982; Friedman et al., 1985). It contained greater than $94 \%$ of the tri-tetra-antennary form, as measured from partitioning on a concanavalin A-Sepharose column and NeuAc content analysis (Friedman et al., 1985) of the retained and eluted species.

\section{Desialylation}

Protein was incubated with $\mathrm{Cl}$. perfringens neuraminidase attached to agarose beads at various temperatures and for various times in $10 \mathrm{~mm}$-acetate buffer, $\mathrm{pH} \mathrm{5.0,} \mathrm{to}$ achieve partially desialylated material. The product was dialysed into water and freeze-dried. The greatest extent of NeuAc removal was approx. $90 \%$, leaving an average of one NeuAc residue attached per protein molecule. Polymer formation was assessed by gel filtration on a Sephacryl S-300 column $(1.0 \mathrm{~cm} \times 117 \mathrm{~cm})$. The partition coefficients $(\sigma)$ of the various preparations were measured by gel filtration on a Sephadex G-75-150 column $(1.6 \mathrm{~cm} \times 95 \mathrm{~cm})$.

\section{U.v. absorption and fiuorescence spectroscopy}

These were performed as described previously (Friedman et al., 1985).

\section{pH titrations}

The intrinsic fluorescence of $1 \mu \mathrm{M}-\mathrm{OMD}$ (in phosphatebuffered saline) was monitored as aliquots of $0.1 \mathrm{M}-\mathrm{HCl}$ were added. Duplicate titrations were performed and the $\mathrm{pH}$ was monitored with addition of $\mathrm{HCl}$. If present, $\mathrm{Cs}^{+}$ and succinimide concentrations were kept constant as the $\mathrm{pH}$ was lowered.

\section{Binding measurements}

Chlorpromazine-binding values were obtained by the method of Hummel \& Dreyer (1962) as described previously (Friedman et al., 1985). The protein concentrations were maintained at $10 \mu \mathrm{M}$.

\section{RESULTS AND DISCUSSION}

Changes occurring within the OMD molecule as a result of the removal of NeuAc are unlikely to be simple, particularly since so many potential sources of change exist. It would appear, though, from the results obtained here that some preliminary conclusions can be drawn.

At the grossest level, the effective hydrodynamic size of the molecule decreases (Fig. 1). This, seen here as a decrease in the gel-filtration partition coefficient, $\sigma$, has

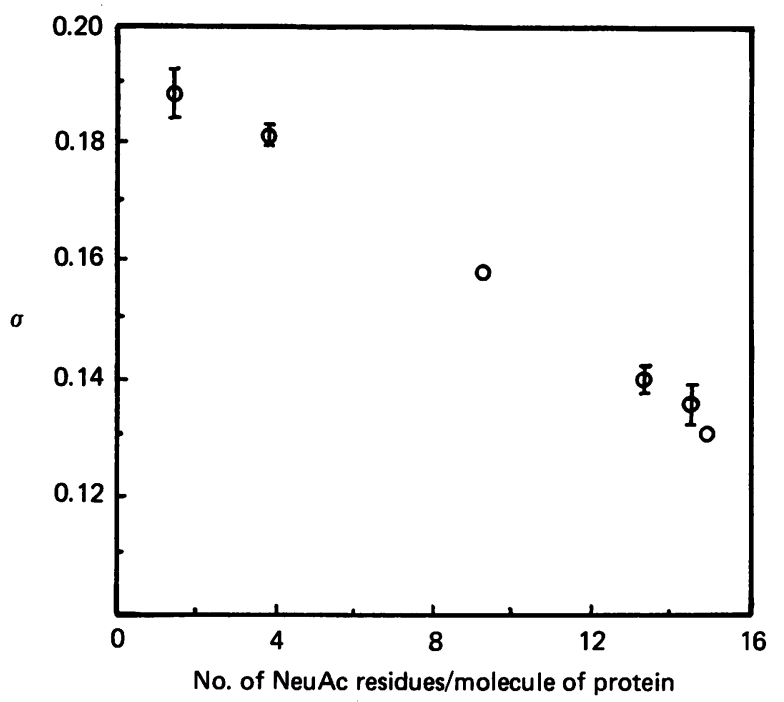

Fig. 1. $\sigma$ values of the partially desialylated OMD

Gel filtration was performed on a G-75-150 column in phosphate-buffered saline, $\mathrm{pH}$ 7.4. A sample loop of $1 \mathrm{ml}$ was used to introduce a $20 \mu \mathrm{M}$-protein sample to the column. The elution volumes were determined by weight and $\sigma$ values were calculated as discussed by Ackers (1970).

Table 1. Quenching of the intrinsic fluorescence of 1.5 NeuAc OMD and native OMD by low- $M_{\mathrm{r}}$ quenchers

The data were obtained as described previously (Friedman et al., 1985). $f_{\mathrm{a}}$ (fraction accessible) and $K_{\mathrm{Q}}$ (effective quenching constant) were obtained from the modified Stern-Volmer plot (Lehrer, 1971):

$$
\frac{F_{0}}{\Delta F}=\frac{1}{\left(f_{\mathrm{a}}\right)\left(K_{\mathrm{Q}}\right)[\mathrm{Q}]}+\frac{1}{f_{\mathrm{a}}}
$$

\begin{tabular}{lcc}
\hline & 1.5 NeuAc OMD & Native OMD \\
\hline Acrylamide & & \\
$f_{\mathrm{a}}$ & 1.055 & 1.075 \\
$K_{\mathbf{Q}}$ & 10.75 & 9.070 \\
Succinimide & & \\
$f_{\mathrm{a}}$ & 0.382 & 0.395 \\
$K_{\mathbf{Q}}$ & 1.04 & 0.948 \\
$\mathrm{Cs}^{+}$ & & \\
$f_{\mathrm{a}}$ & 0.343 & 0.339 \\
$K_{\mathbf{Q}}$ & 2.895 & 2.895 \\
$\mathrm{I}^{-}$ & Less than $5 \%$ quenching for both preparations \\
\hline
\end{tabular}

also been reported from sedimentation data (Kawahara et al., 1973) and can be most reasonably interpreted as resulting from changes in the hydration shell of the molecule. It is extremely unlikely that $\sigma$ changes are due to rearrangement of the polypeptide backbone, and fluorescence-quenching data support this.

Intrinsic fluorescence can be a sensitive indicator of the accessibility and environment of tryptophan residues. OMD contains three tryptophan residues, and it is not unreasonable to suggest that these could act as reporter groups for local conformational change. Quenching of native OMD and 1.5 NeuAc OMD (i.e. OMD containing an average of $1.5 \mathrm{NeuAc}$ residues/molecule) were 


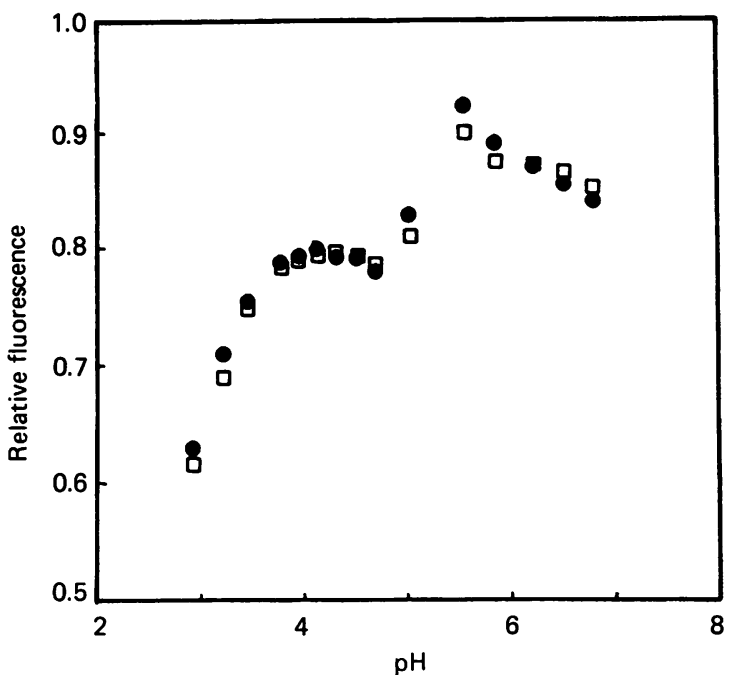

Fig. 2. pH-dependence of native OMD and 1.5 NeuAc OMD fluorescence in the presence of succinimide

The concentrations of native OMD and 1.5 NeuAc OMD for all fluorescence work were maintained at approx. $1 \mu \mathrm{M}$ in phosphate-buffered saline, $\mathrm{pH}$ 7.4. Excitation was at $285 \mathrm{~nm}$, and the fluorescence intensities were measured at $340 \mathrm{~nm}$. The succinimide quenching profiles of native OMD ( $\square$ ) and $1.5 \mathrm{NeuAc}$ OMD (O) were monitored as the $\mathrm{pH}$ was lowered by the addition of $0.1 \mathrm{M}-\mathrm{HCl}$. Succinimide concentrations were maintained at $0.45 \mathrm{M}$. The data points denote the ratio of quenched to unquenched fluorescence at that $\mathrm{pH}$.

compared with the use of $\mathrm{Cs}^{+}, \mathrm{I}^{-}$, acrylamide and succinimide (Table 1). For all quenchers, both the fraction quenched $\left(f_{\mathrm{a}}\right)$ and quenching efficiency $\left(K_{\mathrm{Q}}\right)$ were the same. Fluorescence $\mathrm{pH}$ titrations in the absence and in the presence of quenchers (Figs. 2 and 3 ) also gave essentially identical quenching parameters, even though the microenvironments of one or more tryptophans are sensitive to acid pH below pH 6 (Friedman et al., 1985), and gross conformational changes occur below $\mathrm{pH} 4$ (Karpenko et al., 1968). A dramatic increase in fluorescence intensity is seen for native OMD upon decreasing the $\mathrm{pH}$ from 7.4 (Friedman et al., 1985), but, since this enhancement is also seen with 1.5 NeuAc OMD, it is unlikely to involve the NeuAc residues.

Thus it would appear that removal of NeuAc does not affect the environments of the tryptophan residues of OMD, and therefore, in a molecule this small, conformational changes resulting from NeuAc removal are likely to be small.

Chlorpromazine, dipyridamole and spin-labelled propranolol compete for a single hydrophobic binding domain on OMD (Kirley et al., 1982; R. Magnotti, M. L. Friedman \& H. B. Halsall, unpublished work). The ligandbinding parameters of these ligands with the partially desialylated preparations were examined by using Hummel-Dreyer chromatography, fluorescence spectroscopy and e.s.r. spectroscopy. The results, together with studies by others using equilibrium dialysis, are collected in Table 2. It is apparent that there is very little (if any) change in the affinity of the ligands for NeuAc-poor OMD when compared with native OMD, except for chlorpromazine. With loss of NeuAc, the affinity of chlorpromazine for the partially desialylated preparations

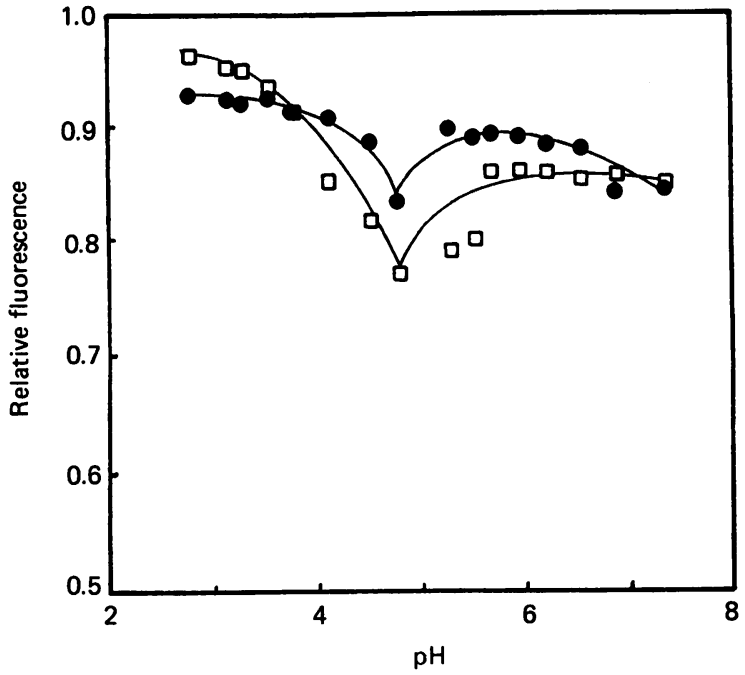

Fig. 3. pH-dependence of native OMD and 1.5 NeuAc OMD fluorescence in the presence of $\mathrm{Cs}^{+}$

The $\mathrm{Cs}^{+}$quenching profiles of native OMD ( $\square$ ) and 1.5 NeuAc OMD (O) were monitored as the $\mathrm{pH}$ was lowered by the addition of $0.1 \mathrm{M}-\mathrm{HCl}$. $\mathrm{Cs}^{+}$concentrations were maintained at $0.45 \mathrm{M}$. The conditions were as described in Fig. 2 legend. The data points denote the ratio of quenched to unquenched fluorescence at that $\mathrm{pH}$. The lines are intended as a visual aid only.

decreases. This decrease is progressive with loss of NeuAc residues (results not shown).

The preparation used for these experiments was greater than $94 \%$ tri-/tetra-antennary, and would therefore be expected from neutron-scattering data ( $\mathrm{Li}$ et al., 1983; Perkins et al., 1985) to have the NeuAc residues folded back in the native molecule and interacting with the protein core. Such a multiplicity of interactions could be expected to add stability to the molecule, and their removal causes of lessening of stability. Calorimetric studies of native OMD and NeuAc-poor OMD (Halsall \& Kirley, 1982) show that, unless such interactions contained a large entropic component, then the removal of NeuAc stabilized OMD. This is supported by the thermal-stability work reported here (Table 3 ), which shows a small but regular increase in $T_{\mathrm{d}}$ with NeuAc removal, and little change in $\Delta H_{\mathrm{vH}}$. These results, together with the fluorescence-quenching data, indicate that strong interactions between NeuAc and the protein core do not exist. Others (Schmid et al., 1976; Puett et al., 1977) have reached a similar conclusion. We cannot rule out the possibility of the existence of interactions between a very limited number of NeuAc residues and the protein core provided that they are distal to the tryptophan residues and do not influence unfolding with $\mathrm{pH}$. The existence of large numbers of NeuAc-protein, and possibly $\mathrm{N}$-acetylglucosamine-protein, interactions, however, seems doubtful under physiological conditions.

Of the physical properties studied, three were NeuAc-content-dependent, $\sigma, T_{\mathrm{d}}$ and association constant for chlorpromazine, and in a monotonic rather than biphasic way. As mentioned above, a straightforward explanation probably exists for the $\sigma$-dependence. In the absence of protein conformational changes, a possible source of the increased thermal stability is an increase in the interaction energy between the glycan inner core and 
Table 2. Ligand-binding association constants to partially desialylated OMD and native OMD

The Table gives the association constants of various ligands for native OMD and partially desialylated OMD, obtained by equilibrium dialysis (Kute \& Westphal, 1976; El Gamel et al., 1982; Wong \& Hsia, 1983), e.s.r. and fluorescence spectroscopy (present work).

Association constants $\left(\mathrm{M}^{-1}\right)$

\begin{tabular}{|c|c|c|c|c|}
\hline \multirow[b]{2}{*}{ Material } & \\
\hline & Chlorpromazine & Dipyridamole & Propranolol & Progesterone \\
\hline $\begin{array}{l}\text { Native OMD } \\
\text { Native OMD } \\
7.5 \text { NeuAc OMD } \\
1.0 \text { NeuAc OMD }\end{array}$ & $\begin{array}{c}1.4 \times 10^{6 *} \\
8.2 \times 10^{5} \pm 1.4 \times 10^{5} \dagger \\
7.7 \times 10^{5 *} \\
1.06 \times 10^{5} \pm 0.06 \times 10^{5} \dagger\end{array}$ & $\begin{array}{c}1.5 \times 10^{7} \pm 1.1 \times 10^{7} \ddagger \\
1.55 \times 10^{7} \ddagger \\
1.75 \times 10^{7} \pm 1.1 \times 10^{7} \dagger\end{array}$ & $\begin{array}{l}8.4 \times 10^{5} \S \\
2.8 \times 10^{6 *} \\
3.2 \times 10^{6 *} \\
6.0 \times 10^{5} \S\end{array}$ & $3.2 \times 10^{5} \|$ \\
\hline \multicolumn{5}{|c|}{$\begin{array}{l}\text { * Measured by e.s.r., with spin-labelled propranolol. } \\
\dagger \text { Measured by fluorescence quenching. } \\
\ddagger \text { Measured by equilibrium dialysis (El Gamel } \text { et al., 1982). } \\
\S \text { Measured by equilibrium dialysis (Wong \& Hsia, 1983). } \\
\| \text { Measured by equilibrium dialysis (Kute \& Westphal, 1976). }\end{array}$} \\
\hline
\end{tabular}

Table 3. Thermal-denaturation studies of partially desialylated OMD

The data were obtained by monitoring the $A_{285}$ with increasing temperature at a rate of $1^{\circ} \mathrm{C} / \mathrm{min}$. The equilibrium constant, $K_{\text {eq. }}$, was calculated assuming a two-state transition. $\Delta H_{\mathrm{vH}}$ was calculated from the slope

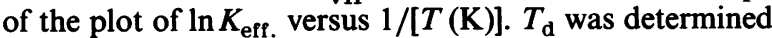
at $\ln K_{\text {eff. }}=0$.

\begin{tabular}{cll}
$\begin{array}{c}\text { No. of NeuAc } \\
\text { residues/ } \\
\text { molecule }\end{array}$ & $T_{\mathrm{d}}\left({ }^{\circ} \mathrm{C}\right)$ & $\Delta H_{\mathrm{vH}}[\mathrm{kJ} / \mathrm{mol}(\mathrm{kcal} / \mathrm{mol})]$ \\
\hline 15 & $66.6 \pm 0.1$ & $320.1 \pm 14.6(76.5 \pm 3.5)$ \\
13.2 & $66.7 \pm 0.3$ & $348.1 \pm 43.5(83.2 \pm 10.4)$ \\
9.15 & 67.6 & 328.4 \\
8.55 & $67.9 \pm 0.2$ & $323.4 \pm 11.3(77.5)$ \\
4.05 & $67.9 \pm 0.7$ & $346.1 \pm 17.6(82.7 \pm 4.2)$ \\
3.87 & $68.7 \pm 0.1$ & $331.8 \pm 4.6(79.3 \pm 1.1)$ \\
1.43 & $69.0 \pm 0.4$ & $325.9 \pm 30.1(77.9 \pm 7.2)$ \\
1.00 & $68.9 \pm 0.7$ & $319.7 \pm 29.7(76.4 \pm 7.1)$
\end{tabular}

the protein, as exists in the Fc fragment of IgG (Sutton $\&$ Phillips, 1983). The binding affinity of chlorpromazine decreases significantly with loss of NeuAc (Table 2). It seems unlikely that the decrease is due to a repositioning of the asialylated glycan chains, or a conformational change in the tryptophan-containing binding domain, since the association constants of the larger competitive ligands progesterone and dipyridamole are unaffected (Table 2). This suggests that an electrostatic interaction exists between the chlorpromazine and the NeuAc residue(s), possibly with the cationic side arm, and permitted by the flexibility of the glycan antennae.

We have noted that assorted biological activities reported for OMD (with glycan chain mixtures) have shown a marked dependency on NeuAc content, there being an inflexion point for activity corresponding to about four or five NeuAc residues remaining/molecule of OMD (Franzblau et al., 1976; Costello et al., 1979a,b; Andersen et al., 1980). Where changes were seen in the present work, they were progressive and occurred through the region where biological changes are not seen.
If the assumption is made that the removal of NeuAc from the OMD surface is relatively random, then changes in physical properties that depended only on the presence of NeuAc would also be expected to be relatively regular, even for co-operative changes, since the critical residue(s) would be removed randomly. This is also likely to be true for changes in activity caused by steric hindrance from the changed mobility of the glycan chains and their screening of the protein surface. Thus the dependence of biological activity on NeuAc content may be in a valence sense such that, when the local charge density is below the contribution of four or five NeuAc residues, activity is decreased. This might be especially true if the charge distribution in the holo-OMD is asymmetric. Unless the site(s) of biological activity were distal from the tryptophan residues, it is difficult to see how the reported losses in biological activity could be due to changes in interaction with the protein core as a result of screening or conformational change. A simple NeuAc charge involvement has been proposed in other systems as well (Amr et al., 1982).

M.L.F. acknowledges the award of a University of Cincinnati Research Council Summer Research Fellowship.

\section{REFERENCES}

Ackers, G. (1970) Adv. Protein Chem. 24, 343-446

Amr, S., Shimohigashi, Y., Carayon, P., Chen, H.-C. \& Nisula, B. (1982) Biochem. Biophys. Res. Commun. 109, 146-151

Andersen, P., Andersen, S. \& Brosstad, F. (1980) Thromb. Res. $17,865-871$

Bayard, B. \& Kerckaert, J.-P. (1980) Biochem. Biophys. Res. Commun. 95, 777-784

Costello, M., Baum, L., Hansen, B. \& Gewurz, H. (1979a) Fed. Proc. Fed. Am. Soc. Exp. Biol. 38, 1365

Costello, M., Fiedel, B. A. \& Gewurz, H. (1979b) Nature (London) 281, 677-678

El Gamel, S., Wollert, U. \& Muller, W. E. (1982) J. Pharm. Pharmacol. 34, 152-157

Franzblau, C., Schmid, K., Faris, B., Beldekas, J., Garvin, P., Kagan, H. M. \& Baum, B. J. (1976) Biochim. Biophys. Acta 427, 302-314

Friedman, M. J. (1983) Proc. Natl. Acad. Sci. U.S.A. 80, $5421-5424$ 
Friedman, M. L. Schlueter, K. T., Kirley, T. L. \& Halsall, H. B. (1985) Biochem. J. 232, 863-867

Halsall, H. B. \& Kirley, T. L. (1982) Arch. Biochem. Biophys. 216, 392-399

Halsall, H. B., Kirley, T. L. \& Friedman, M. L. (1982) Prep. Biochem. 6, 2801-2814

Hummel, J. P. \& Dreyer, W. S. (1962) Biochim. Biophys. Acta $63,530-532$

Karpenko, V., Pavlicek, Z. \& Kalous, V. (1968) Biochim. Biophys. Acta 154, 245-247

Kawahara, K., Ikenaka, T., Nimberg, R. B. \& Schmid, K. (1973) Biochim. Biophys. Acta 295, 505-513

Kirley, T. L., Sprague, E. D. \& Halsall, H. B. (1982) Biophys. Chem. 15, 209-216

Kute, T. \& Westphal, U. (1976) Biochim. Biophys. Acta 420, 195-213

Lawson, E. Q., Hedlund, B. E., Ericson, M. E., Mood, D. A., Litman, G. W. \& Middaugh, R. (1983) Arch. Biochem. Biophys. 220, 572-575

Lehrer, S. S. (1971) Biochemistry 10, 3254-3263

Li, Z. Q., Perkins, S. J. \& Loucheux-Lefebvre, M. H. (1983) Eur. J. Biochem. 130, 275-279
Marshall, J. S. \& Williams, S. (1978) Biochim. Biophys. Acta 543, 41-52

Montreuil, J. (1982) Compr. Biochem. 19B, 1-189

Olden, K., Parent, J. B. \& White, S. (1982) Biochim. Biophys. Acta 650, 209-232

Perkins, S. J., Kerckaert, J.-P. \& Loucheux-Lefebvre, M. H. (1985) Eur. J. Biochem. 147, 525-531

Puett, D., Holladay, L. A., Ford, J. D. \& Cunningham, L. W. (1977) Biochim. Biophys. Acta 491, 129-136

Reutter, W., Kottengen, E., Bauer, C. \& Gerok, W. (1982) in Sialic Acid Chemistry, Metabolism and Function (Schauer, R., ed.), pp. 263-307, Springer-Verlag, New York

Rudman, D., Treadwell, P. E., Vogler, R., Howard, C. H. \& Hollins, B. (1972) Cancer Res. 32, 1951-1959

Schmid, K., Chen, L.-C. H.\&Occhino, J. C. (1976) Biochemistry 15, 2245-2253

Sutton, B. J. \& Phillips, D. C. (1983) Biochem. Soc. Trans. 11, $130-132$

Varghese, J. N., Laver, W. G. \& Colman, P. M. (1983) Nature (London) 303, 35-40

Wong, A. K. L. \& Hsia, J. C. (1983) Can. J. Biochem. Cell Biol. 61, 1114-1116

Received 9 August 1985/19 December 1985; accepted 10 January 1986 